\title{
Temporal variation of the small eukaryotic community in two freshwater lakes: emphasis on zoosporic fungi
}

\author{
Emilie Lefèvre ${ }^{1,2, *}$, Peter M. Letcher ${ }^{1}$, Martha J. Powell ${ }^{1}$ \\ ${ }^{1}$ Department of Biological Sciences, The University of Alabama, Tuscaloosa, Alabama 35487, USA \\ ${ }^{2}$ Present address: Department of Biology, Duke University, Durham, North Carolina 27701, USA
}

\begin{abstract}
Applications of molecular approaches to the study of microbial eukaryotic communities in freshwater lakes are transforming our understanding of these ecosystems. One of the most unexpected discoveries is that zoosporic fungi significantly dominate the planktonic fungal diversity. Although zoosporic fungi are now recognized as an important component of aquatic microbial food webs, our knowledge of their community structure and temporal variability remains poor. The objectives of our study were (1) to compare and describe the contribution of zoosporic fungi to the eukaryotic diversity in 2 lakes differing in their trophic status during the mixing and the stratified seasons and (2) to phylogenetically identify the recovered zoosporic fungal sequences. The small eukaryotes $(0.6$ to $8 \mu \mathrm{m})$ of the euphotic zone of the oligotrophic Lake Tuscaloosa and meso-eutrophic Lake Lurleen (Alabama, USA) were collected over 1 yr. Analyses of the 28S rDNA clone libraries showed that zoosporic fungi dominated the small planktonic fungal community and were more diverse in the meso-eutrophic lake and during the thermal stratification. Although the overall structure of the eukaryotic community was similar between the 2 lakes, at lower taxonomic levels, community composition differed. Analyses of the retrieved fungal sequences revealed that zoosporic fungi mostly affiliated with Rhizophydiales and Chytridiales or formed environmental clades. Although the phytoplanktonic community was also monitored, zoosporic fungal parasites were rarely observed on algae. These results provide new insights into the diversity and seasonality of the zoosporic fungal community in lake ecosystems.
\end{abstract}

KEY WORDS: Zoosporic fungi · Molecular diversity · Temporal variation $\cdot$ Freshwater lakes $\cdot$ Plankton

Resale or republication not permitted without written consent of the publisher

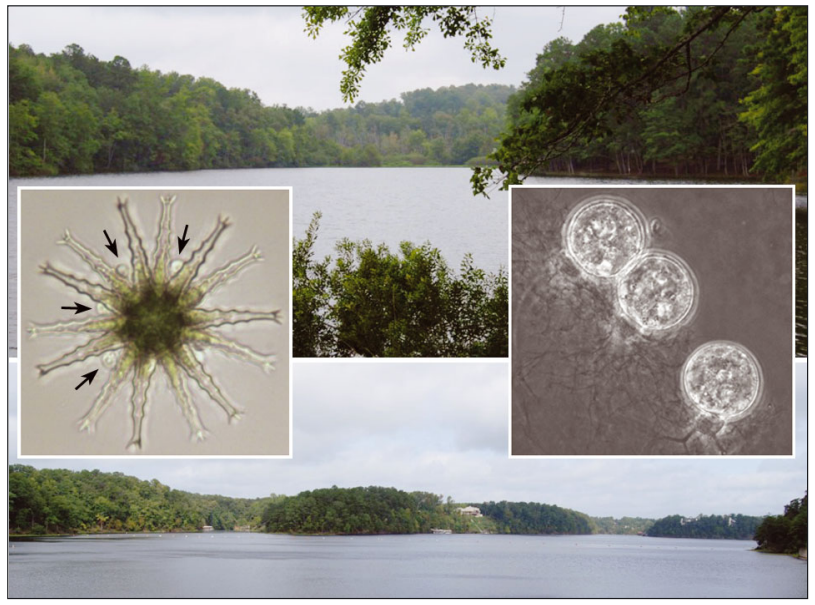

The meso-eutrophic Lake Lurleen (top) and humic oligotrophic Lake Tuscaloosa (bottom) harbor a high diversity of planktonic zoosporic fungi, such as the saprobe Rhizoclosmatium aurantiacum (right: young sporangia in culture) and the unidentified parasite (arrows) on the alga Straurastrum rotula (left: individual in environmental sample).

Photos: MJ Powell, PM Letcher, E Lefèvre

\section{INTRODUCTION}

Recent applications of molecular approaches to characterize eukaryotic communities have revealed that zoosporic fungi significantly contribute to the eukaryotic diversity in a range of ecosystems, such as high-elevation soils (Freeman et al. 2009), deep-sea hydrothermal ecosystems (Le Calvez et al. 2009, Nagahama et al. 2011), and streams (Nikolcheva \& Bärlocher 2004, Seena et al. 2008). In freshwater lakes, 
where fungi in general have rarely been factored in as a component of the microbial food web (Wetzel 2001, Sigee 2005), a high diversity of zoosporic fungal sequences has been unexpectedly recovered in recent studies (Lefranc et al. 2005, Slapeta et al. 2005, Lefèvre et al. 2007, 2008, Lepère et al. 2008, Chen et al. 2008, Luo et al. 2011, Monchy et al. 2011).

The typical life cycle of a zoosporic fungus begins with the attachment of a free-swimming uniflagellate zoospore to decaying or living organic substrates. The encysted zoospore develops into a mature thallus (sporangium typically with rhizoids) obtaining its energy from the substrate. When the thallus reaches maturity, the sporangium releases zoospores (typically 3 to $8 \mu \mathrm{m}$ diameter) into the environment (Fuller \& Jaworski 1987, Powell 1993). Multiple roles for zoosporic fungi in lake ecosystems have been suggested, including (1) parasites affecting phytoplanktonic successions and impacting primary production, (2) saprobes playing an important role in decomposition of recalcitrant organic material such as chitin and cellulose, and (3) prey, via the consumption of their zoospores by predators, transferring energy from primary producers and detritus to highertrophic-level organisms (reviewed by Gleason et al. 2008). However, data supporting these assumptions are relatively scarce (van Donk \& Ringelberg 1983, Kagami \& Urabe 2002, Kagami et al. 2004, 2007a, Rasconi et al. 2009), and consequently little is known about the ecological importance and dynamics of zoosporic fungi in freshwater lakes.

In contrast, phylogenetics has advanced in the past decade with an impressive amount of molecular and ultrastructural data assembled for zoosporic fungi sampled globally (Letcher \& Powell 2005a,b, Letcher et al. 2005, 2006, 2008a,b, James et al. 2006a,b, Mozley-Standridge et al. 2009, Simmons et al. 2009, Wakefield et al. 2010, Vélez et al. 2011). These analyses have profoundly improved our understanding of the phylogenetic relationships and diversity of zoosporic fungi. However, the majority of sequences recovered from lakes have not matched any described zoosporic fungi and do not affiliate with any known zoosporic fungal taxa. These results suggest that lakes harbor a high and largely unexplored zoosporic fungal diversity that perhaps represents novel phylogenetic lineages.

In this context, the present study had 2 main objectives: (1) from an ecological standpoint, to describe the community structure of freshwater zoosporic fungi in 2 lakes differing in their trophic status and the dynamics of the recovered diversity during 2 contrasted seasons of the year; and (2) from a phyloge- netic standpoint, to explore the diversity of freshwater zoosporic fungi and accurately place the recovered sequences within the zoosporic fungal phylogeny. To address these objectives, an rDNA environmental survey was conducted on the small planktonic fraction $(0.6$ to $8 \mu \mathrm{m})$. The small planktonic fraction was selected in order to relate the detected diversity to similar previous studies also conducted on the small fraction, which harbors a relatively high diversity of zoosporic fungi (Lefranc et al. 2005, Lefèvre et al. 2007, 2008, Lepère et al. 2008) (see Table 2). Because of the exploratory aspect of our study for undescribed zoosporic fungi, we chose to use universal eukaryotic primers instead of more specific fungal primers designed from mostly terrestrial and non-zoosporic fungi (White et al. 1990, Borneman \& Hartin 2000). In addition, although the main goal of the present study focused on the zoosporic fungal community, the use of universal eukaryotic primers provided an overview of the small eukaryotic community, therefore giving us the opportunity to place the recovered zoosporic fungal diversity in the context of the whole eukaryotic community. Finally, to address our second objective, we chose to target the ribosomal large subunit (LSU, i.e. 28S) gene, which has been shown to be more phylogenetically informative for zoosporic fungi than the more conserved small subunit (SSU, i.e. 18S) gene or the more variable ITS region (Letcher et al. 2008a, $\mathrm{b}, \mathrm{c})$. In addition, to characterize the fungal parasitism potentially associated with algae, the composition and dynamics of the phytoplanktonic community were microscopically determined.

\section{MATERIALS AND METHODS}

\section{Study sites and sampling}

Lake Tuscaloosa (LT) and Lake Lurleen (LL) are 2 freshwater reservoirs situated in the Black Warrior River basin, Alabama, USA (Ward et al. 2005). LT has a surface area of $24 \mathrm{~km}^{2}$ and a maximum depth of $30 \mathrm{~m}$, while LL has a surface area of $1 \mathrm{~km}^{2}$ and a maximum depth of $10 \mathrm{~m}$. Samplings and measurements were taken every 1 to 2 wk from December 2007 to November 2008 (LT) and from October 2008 to November 2009 (LL) at a central point in each lake (LT: $33^{\circ} 17^{\prime} 24.61^{\prime \prime} \mathrm{N}, 87^{\circ} 30^{\prime} 41.43^{\prime \prime}$ W; LL: 33 $17^{\prime}$ $\left.27.65^{\prime \prime} \mathrm{N}, 87^{\circ} 30^{\prime} 40.51^{\prime \prime} \mathrm{W}\right)$. Temperature and dissolved oxygen vertical profiles were obtained using a YSI550A multiparameter probe (YSI). To describe the phytoplanktonic community and characterize the 
fungal parasitism potentially associated with this community, phytoplanktonic samples were collected in triplicate using a vertical plankton tow $(60 \mu \mathrm{m}$ mesh size) from the bottom of the euphotic zone (approximated using a Secchi disc) to the surface. In the laboratory, phytoplanktonic samples were processed following the protocol described by Wetzel \& Likens (1990). Cells were observed using a Nikon Labophot-2 microscope and identified using identification keys from Smith (1950) and Wehr \& Sheath (2003). Biovolumes were calculated using equations provided by Hillebrand et al. (1999), and a ratio of cellular organic carbon to cell volume of 0.1 was used to estimate phytoplanktonic biomass (Wetzel \& Likens 1990). Water samples for molecular analysis and chlorophyll a measurements were collected in triplicate every meter from the bottom of the euphotic zone (varying from 2 to $5 \mathrm{~m}$ and 1 to $3 \mathrm{~m}$ for LT and LL, respectively, see Fig. 1) to the subsurface using a 1 l Van Dorn bottle. For each replicate, water from the different depths sampled was pre-filtered through a $150 \mu \mathrm{m}$ mesh size nylon filter and pooled into an 81 carboy. In the laboratory, water samples for chlorophyll a analysis were filtered through glass fiber filters, and chlorophyll a was extracted using the acetone extraction method (Wetzel \& Likens 1990). Trophic state indices (Carlson 1977) were calculated based on Secchi depth and chlorophyll a concentrations. For molecular analysis, $200 \mathrm{ml}$ of water from 1 replicate was pre-filtered through $8 \mu \mathrm{m}$ poresize carbonate filters by gravity, and cells of interest $(<8 \mu \mathrm{m})$ were collected on $0.6 \mu \mathrm{m}$ pore-size polycarbonate filters using an electric vacuum pump. Filters were stored at $-80^{\circ} \mathrm{C}$ until DNA extraction.

\section{Molecular analysis}

For each lake, 1 replicate of the samples collected during the summer thermal stratification (LT: 7 samples collected from June to September 2008, LL: 8 samples collected from June to September 2009) and the winter mixing (LT: 8 samples collected from January to March 2008, LL: 5 samples collected from December 2008 to February 2009) were processed for DNA extraction. For the cell lysis, filters were incubated with $573 \mu$ of TE (Tris-EDTA: 1 mM EDTA, $10 \mathrm{mM}$ Tris- $\mathrm{HCl}$ ), Proteinase $\mathrm{K}$ and RNase A (both at $0.1 \mathrm{mg} \mathrm{ml}^{-1}$ final concentration), and $0.5 \%$ SDS at $37^{\circ} \mathrm{C}$. After $1 \mathrm{~h}$ incubation, $75 \mu \mathrm{l}$ of chloroform was added, the mixture was briefly vortexed and centrifuged at $11000 \times g$ for $2 \mathrm{~min}$, and the DNAcontaining aqueous phase was collected. The DNA purification was performed using the NucleoSpin Plant kit (Macherey-Nagel). DNA was quantified using a Nanodrop ND-1000 (NanoDrop Technologies), and its integrity (i.e. unsheared high molecular weight DNA) was checked on a $1 \%$ agarose gel. For each sample, a partial 28S ( 900 base pairs) fragment was amplified using LROR (5'-ACC CGC TGA ACT TAA GC-3') and LR5 (5'-TCC TGA GGG AAA CTT CG-3') eukaryotic primers (Vilgalys \& Hester 1990). PCR reactions were performed in $50 \mu$ l containing distilled $\mathrm{H}_{2} \mathrm{O}, 2.5$ to $5 \mathrm{ng}$ of DNA, $200 \mu \mathrm{mol} \mathrm{l}^{-1}$ of each

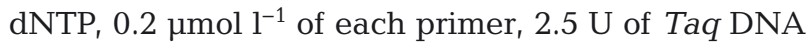
polymerase, and 1X NEB ThermoPol Buffer (New England Biolabs). The PCR program consisted of 2 min at $94^{\circ} \mathrm{C}$, followed by 30 cycles of $1 \mathrm{~min}$ at $94^{\circ} \mathrm{C}$, $1 \mathrm{~min}$ at $50^{\circ} \mathrm{C}$, and $1 \mathrm{~min}$ at $72^{\circ} \mathrm{C}$, and a final extension of $10 \mathrm{~min}$ at $72^{\circ} \mathrm{C}$ (MJ Research PTC-200 thermocycler, Bio-Rad). For each lake, PCR products from the same season were pooled together and purified using the NucleoSpin Extract II kit (MachereyNagel). Four clone libraries (LT summer thermal stratification, LT winter mixing, LL summer thermal stratification, and LL winter mixing) were constructed using the TOPO-TA cloning kit (Invitrogen). For each library, 200 clones were randomly selected and amplified using the primers LROR and LR5. A restriction fragment length polymorphism (RFLP) was performed directly on the PCR products of the positive clones (i. e., containing a 900 base pair DNA insert) using the enzymes MspI and AluI (New England Biolabs). Enzymatic restriction was performed overnight at $37^{\circ} \mathrm{C}$, and profiles were checked on a $2.5 \%$ NuSieve 3:1 agarose (Lonza) gel. Clones presenting the same restriction profile were grouped as an operational taxonomic unit (OTU). One representative of each OTU was sequenced by Macrogen USA. The program Analytic Rarefaction (http://strata.uga.edu/ software/index.html) was used to construct species accumulation curves (Fig. S1 in the supplement at www.int-res.com/articles/suppl/a067p091_supp.pdf), and SPADE (http://chao.stat.nthu.edu.tw/softwareCE .html) was used to estimate the coverage of our samples (Lee \& Chao 1994) (see Table 1).

\section{Phylogenetic analysis}

A Blast search (http://blast.ncbi.nlm.nih.gov/Blast. cgi? CMD=Web\&PAGE_TYPE=BlastHome) was performed to affiliate the recovered sequences. Zoosporic fungal sequences (Table S1 in the supplement) were aligned using ClustalX (Thompson et al. 1997) and BioEdit (Hall 1998). Maximum parsimony (MP) 
and Maximum likelihood (ML) phylogenetic trees were constructed. MP trees were constructed using PAUPRat (Sikes \& Lewis 2001); a majority rule consensus tree was constructed, and branch support was determined as described by Letcher et al. (2004a). From ModelTest (v.3.7) (Posada \& Crandall, 1998), the Akaike information criterion was used to determine the most appropriate model of DNA substitution. ML analyses were performed in GARLI v.0.951 (Zwickl 2006) (www.bio.utexas.edu/faculty/antisense/ garli/Garli.html). The run was repeated 10 times from random starting trees using the auto-terminate setting to determine the best ML tree. Of the 10 trees produced, 3 were equally likely. GARLI was also used to generate $100 \mathrm{ML}$ nonparametric bootstrap replicates from which a majority-rule consensus tree was calculated in PAUP* 4.0b10 (Swofford 2002). Trees were rooted with the choanoflagellate Monosiga ovata.

\section{Zoosporic fungal isolation}

Samples for zoosporic fungal isolation were collected in both lakes in February 2008 on 1 occasion using a vertical plankton tow ( $60 \mu \mathrm{m}$ mesh size). The particulate organic material collected was baited with sweet gum (Liquidambar sp.) pollen, onion skin, and shrimp exoskeleton (Fuller \& Jaworski 1987). Isolated species were identified based on microscopic observation of the thallus and identification keys (Sparrow 1960). Cultures were grown and DNA extracted as described by Letcher et al. (2004a). Partial 28S rDNA was amplified and sequenced with the LROR and LR5 primers.

\section{Sequences accession numbers}

Nucleotide sequences obtained in the present study were deposited in GenBank under accession numbers JN049527 to JN049529 and JN049533 to JN049557.

\section{RESULTS}

\section{Physicochemical and biological characteristics of the study sites}

LT and LL exhibited the same pattern in regards to their seasonal stratification regime, with complete mixing of the water column occurring in winter- spring and thermal stratification in summer-fall (Fig. 1). Temperature profiles (Fig. 1) showed that both lakes were monomictic and holomictic. Dissolved oxygen profiles and chlorophyll a measurements, however, showed remarkable differences between the 2 lakes. While LT displayed a metalimnetic oxygen minimum during summer stratification, LL displayed a metalimnetic oxygen maximum. Chlorophyll a concentrations in LL $\left(9.33 \pm 0.24 \mu \mathrm{g} \mathrm{l}^{-1}\right)$ annually averaged $\sim 6$-fold higher those in LT $(1.55 \pm$

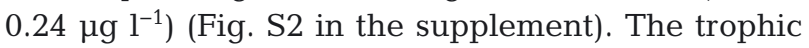
state indices (Carlson 1977) (Fig. S3 in the supplement) demonstrated that LT was oligotrophic and LL was meso-eutrophic (i.e. between mesotrophic and eutrophic). Phytoplankton richness extended across cyanobacteria and 5 groups of photosynthetic eukaryotes (Fig. 2). In total, 59 species were identified in LT and 79 in LL (Table S2 in the supplement). Only 15 algal species were common to both lakes. The annual average phytoplanktonic biomass was $2.8 \mathrm{mg} \mathrm{Cl}^{-1}$ in LT and $125 \mathrm{mg} \mathrm{Cl}^{-1}$ in LL. In LT during the mixing season, 2 species of centric diatoms, Urosolenia sp. and Cyclotella sp., dominated the phytoplanktonic community, accounting for $92 \%$ of the total biomass. In LL during the mixing season, Synura uvella represented $51 \%$ of the phytoplanktonic biomass. During the stratified season, 2 species of dinophytes, Peridinium sp. and Gymnodinium sp., and 2 species of filamentous cyanobacteria, Planktothrix sp. and Planktolyngbya limnetica, represented $90 \%$ of the phytoplanktonic biomass. In our microscopic examination of the phytoplankton in LT and LL, fungal sporangia were occasionally observed on several algal species (Staurastrum rotula, Synedra acus, Cyclotella sp., Synura uvella, Oocystis lacustris, Botryococcus braunii, and Arthrodesmus sp.) (Fig. 3, Table S2). However, the observation of infected algal cells was infrequent during the time of the present study. In addition, because of the lack of distinctive morphological features displayed by zoosporic fungi (Powell 1993, Kagami et al. 2012), microscopic observation of the thallus did not allow us to identify the observed organisms at the species level.

\section{Small eukaryotic diversity}

In our study, 4 clone libraries were constructed. A total of 455 positive clones were analyzed, yielding 119 unique OTUs (Table 1). Although none of the accumulation curves generated reached an asymptote (Fig. S1 in the supplement), coverage estimates (between 73.2 and $94.7 \%$ ) (Table 1) indicated that 


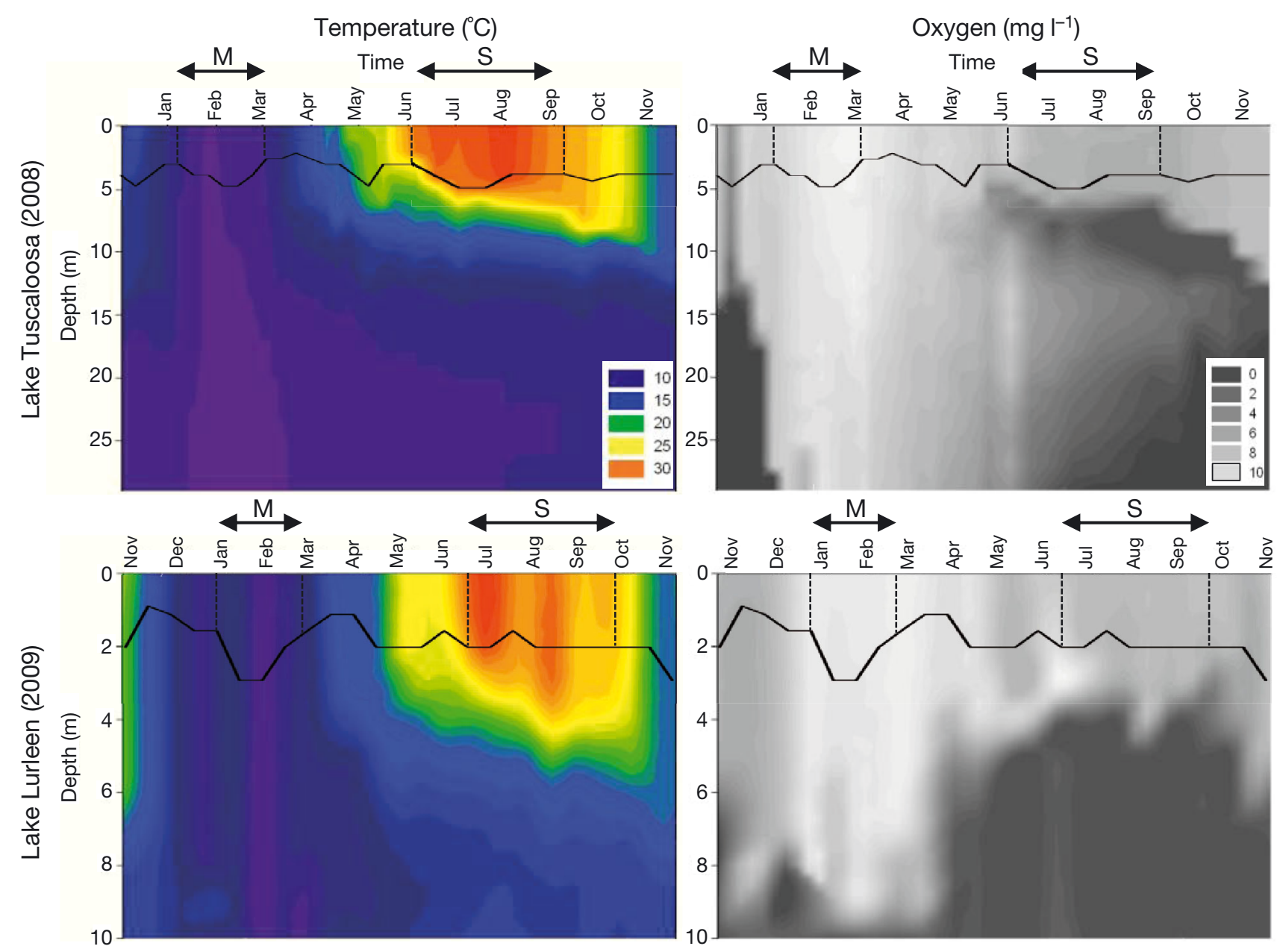

Fig. 1. Temperature (left) and oxygen concentration (right) isopleths for Lake Tuscaloosa (from December 2007 to November 2008, upper) and Lake Lurleen (from November 2008 to November 2009, lower). Secchi depth is represented by a black line. Sampling depths and seasons (M: mixing season, S: stratified season) covered by our molecular survey are delimited by vertical dashed black lines and horizontal arrows, respectively

the eukaryotic community was relatively well sampled. Among the 119 sequences generated in the present study, only 11 had $\geq 97 \%$ identity to identified organisms in GenBank. The BLAST of the 119 sequences indicated that a majority ( 74 to $79 \%$ ) affil- iated with 4 phylogenetic groups: Fungi, alveolates, stramenopiles, and cryptophytes, which were found in both lakes during both seasons (Fig. 4). The remaining sequences (i.e. 'other groups'; Fig. 4) were related to Cercozoa, Katablepharida, Telonema, Cen-

Table 1. Results of the RFLP analysis for the 4 libraries constructed from Lake Tuscaloosa and Lake Lurleen. Dissolved oxygen and temperature averaged over the 2 sampling seasons for each lake are indicated. Sample coverage was calculated using the program SPADE (http://chao.stat.nthu.edu.tw/softwareCE.html)

\begin{tabular}{|lcccccccc|}
\hline Lake & $\begin{array}{c}\text { Trophic } \\
\text { status }\end{array}$ & $\begin{array}{c}\text { Thermal } \\
\text { condition }\end{array}$ & $\begin{array}{c}\text { Oxygen } \\
\left(\mathrm{mg} \mathrm{l}^{-1}\right)\end{array}$ & $\begin{array}{c}\text { Temperature } \\
\left({ }^{\circ} \mathrm{C}\right)\end{array}$ & $\begin{array}{c}\text { No. of OTUs/ } \\
\text { positive } \\
\text { clones }\end{array}$ & $\begin{array}{c}\text { No. of } \\
\text { unique } \\
\text { OTUs }\end{array}$ & $\begin{array}{c}\text { OTUs shared } \\
\text { between } \\
\text { seasons }\end{array}$ & $\begin{array}{c}\text { Sample } \\
\text { coverage } \\
(\%)\end{array}$ \\
\hline Lake & Oligotrophic & Mixing & 10.1 & 10.8 & $29 / 109$ & 25 & 4 & 87 \\
Tuscaloosa & & Stratified & 6.8 & 28.4 & $38 / 102$ & 30 & 86.3 \\
Lake & Meso- & Mixing & 11 & 9.8 & $22 / 132$ & 19 & 1 & 94.7 \\
Lurleen & eutrophic & Stratified & 7.6 & 28.8 & $52 / 112$ & 45 & 73.2 \\
\hline
\end{tabular}




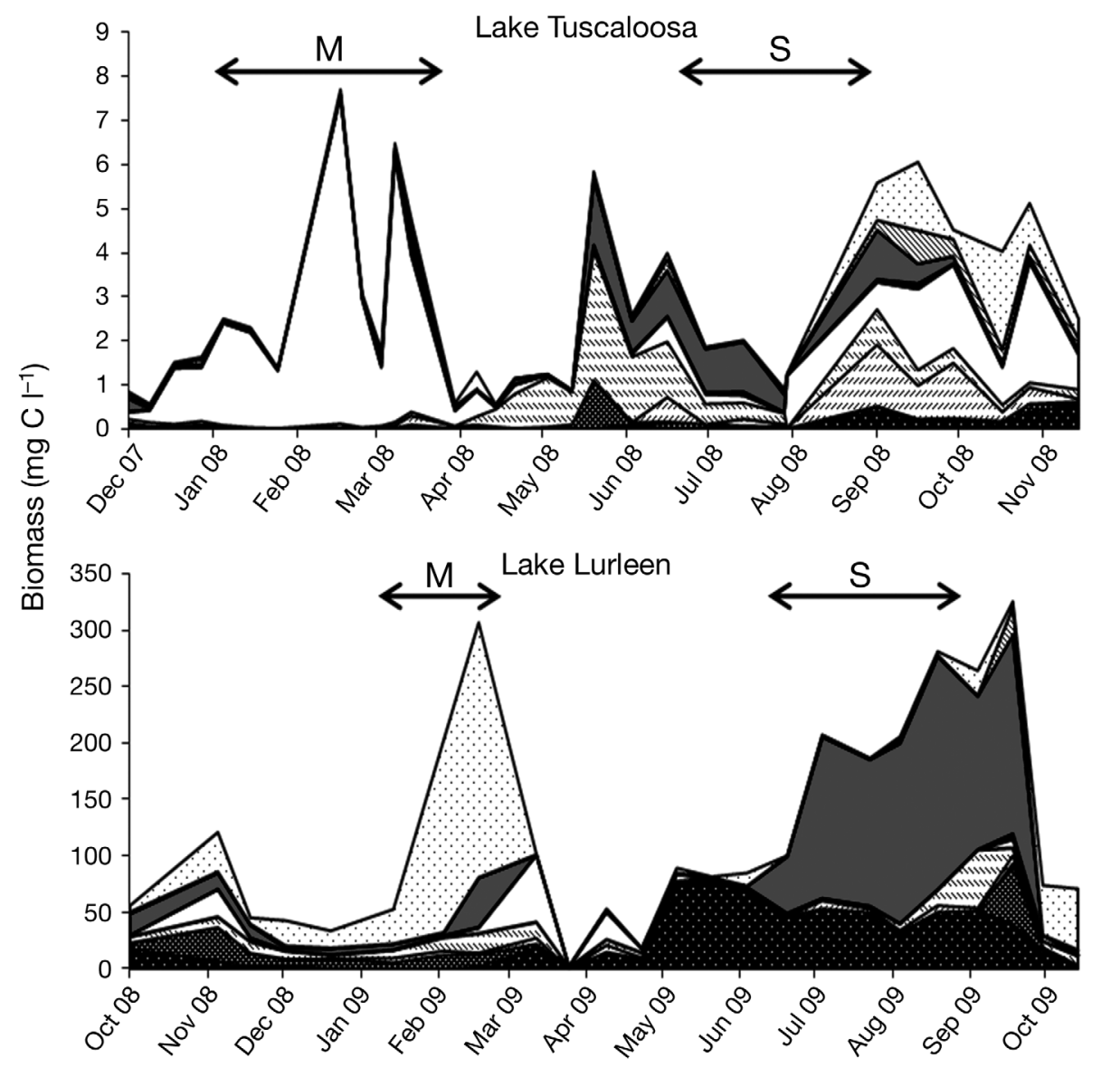

Euglenoids

Chrysophytes

Dinophytes

Pennate diatoms

Centric diatoms

Desmids (green algae)

Other green algae

Coccoid Cyanobacteria

Filamentous Cyanobacteria

Fig. 2. Phytoplanktonic biomass and composition of the euphotic zone of Lake Tuscaloosa and Lake Lurleen. Sampling periods covered by our molecular survey are delimited by horizontal arrows (M: mixing season, S: stratified season)
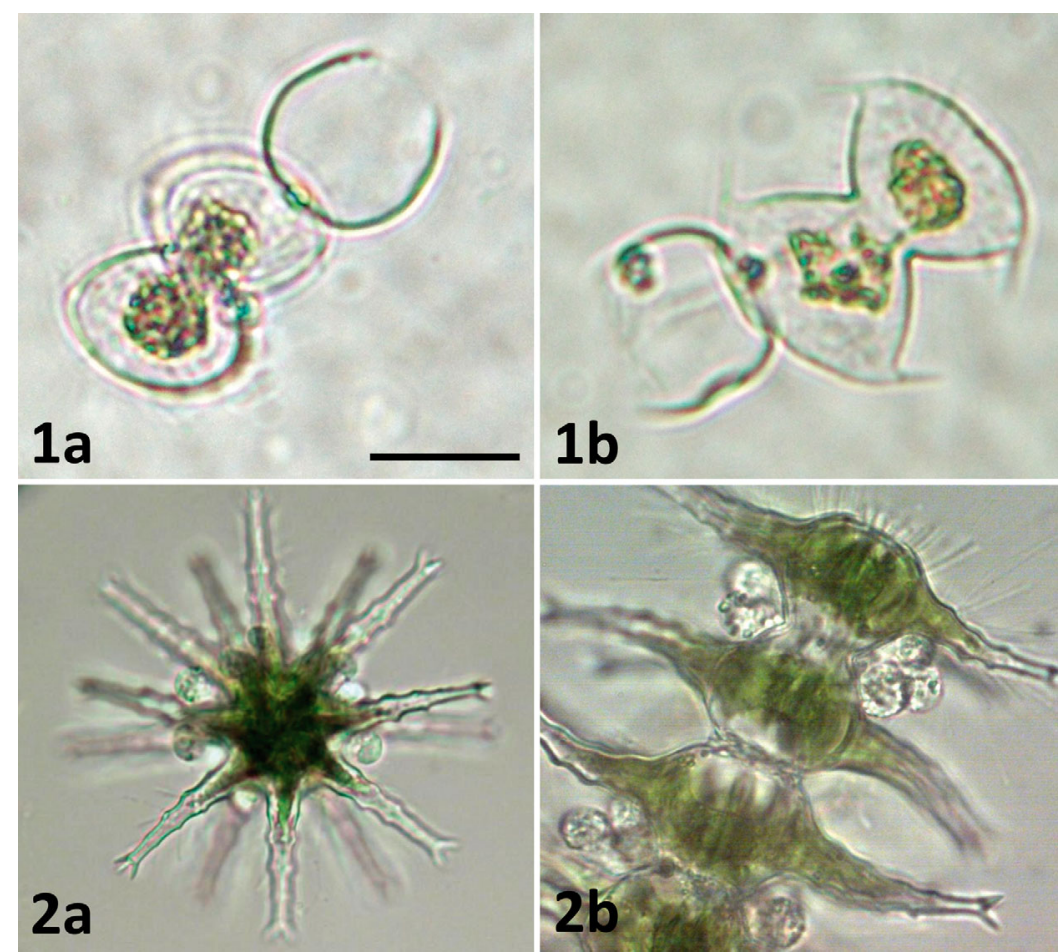

trohelizoa, Euglenozoa, Ichthyosporea, Glaucophyta, and Chlorophyta and were each represented in a relatively low proportion $(\leq 2 \%)$. In each library, a majority of the sequences recovered (72 to $84 \%$ ) belonged to taxa whose primary mode of nutrition was heterotrophy (Fig. 4). Only 7 $(6 \%)$ of the 119 unique OTUs were found in both lakes. Few OTUs were recovered from both the mixing and stratified periods, with only 4 in LT and only 1 in LL. Overall, the number of unique OTUs recovered was

Fig. 3. Micrographs of algae bearing fungal sporangia observed in Lake Tuscaloosa: $(1 \mathrm{a}, \mathrm{b})$ Arthrodesmus sp. bearing an empty fungal sporangium (observed in September 2008), (2a,b) Staurastrum rotula bearing several developing fungal sporangia (observed in November 2008). Scale bar $=25 \mu \mathrm{m}$ for $1 \mathrm{a}, \mathrm{b} \& 2 \mathrm{a}$ and $50 \mu \mathrm{m}$ for $2 b$ 
Lake Tuscaloosa

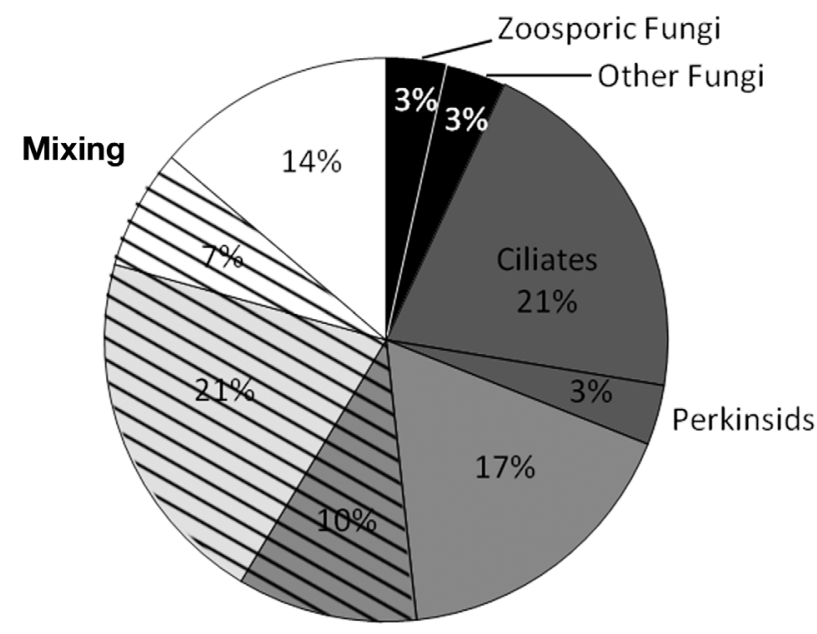

Lake Lurleen

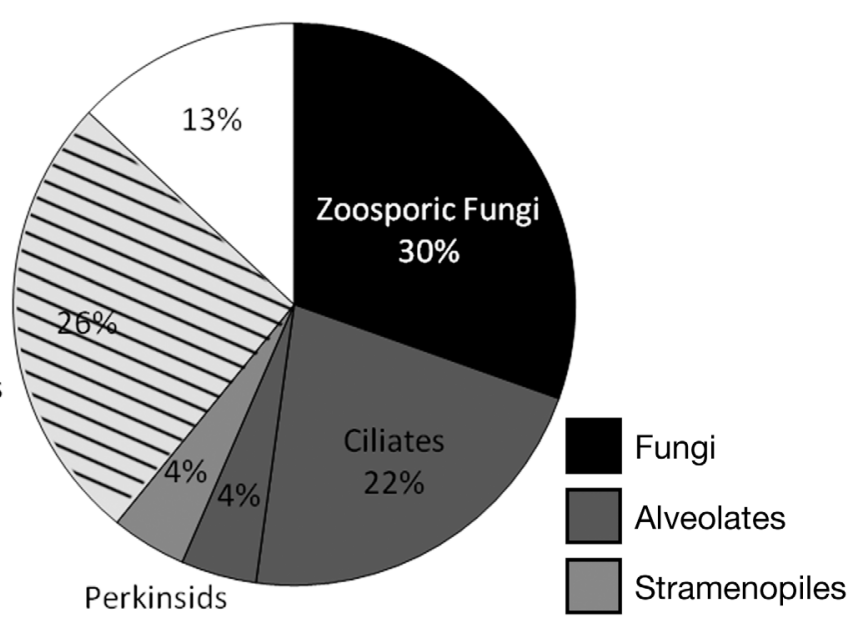

Cryptophytes

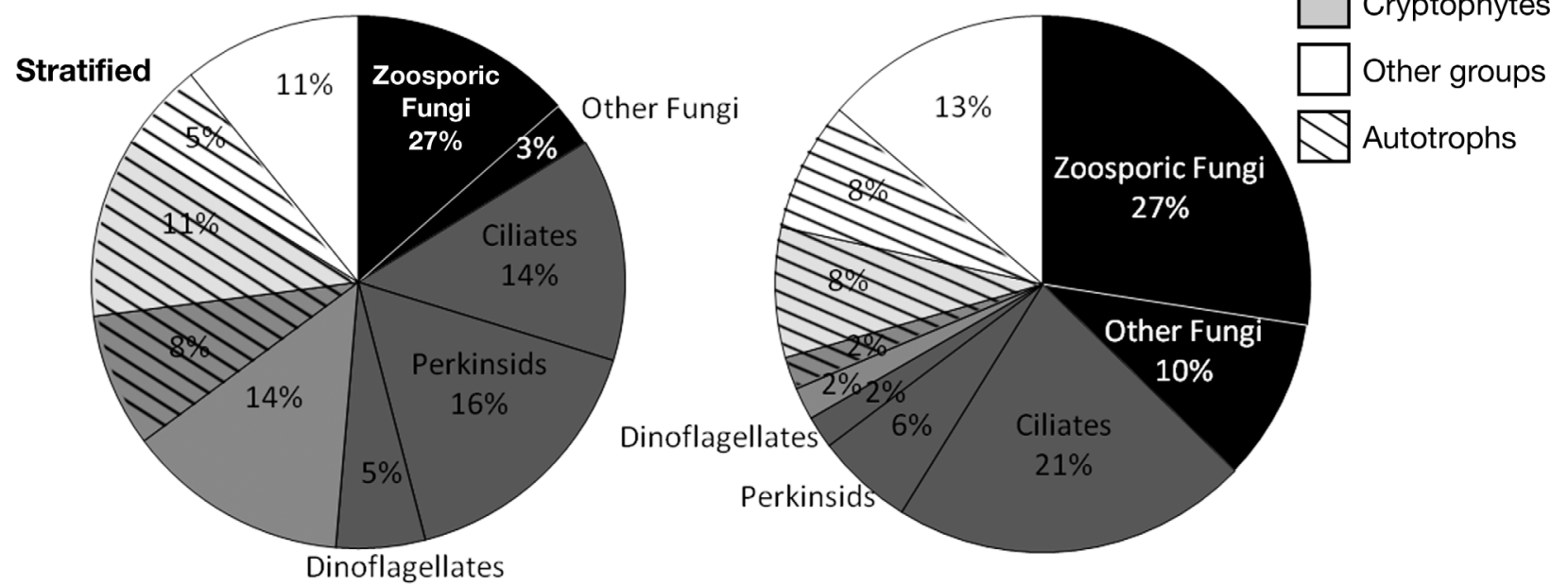

Fig. 4. Relative abundances of OTUs recovered from the 4 clone libraries constructed in the present study. OTUs were grouped into main phylogenetic groups based on BLAST search of the partial LSU rRNA gene

slightly higher in LL (73 OTUs for 244 clones analyzed) than in LT (63 OTUs for 211 clones analyzed). When only seasons were considered, the number of OTUs recovered during the stratified seasons was 1.7-fold greater than during the mixing season (i.e. 90 OTUs of 214 clones analyzed during the stratified season and 51 OTUs of 241 clones analyzed during the mixing season) (Table 1).

\section{Zoosporic fungal diversity and phylogeny}

A total of 31 unique fungal sequences were recovered from the clone libraries (25 zoosporic fungi and 6 other fungi). Only 3 of these sequences were similar $(\geq 97 \%)$ to previously described and sequenced fungal species (1 Basidiomycetes Oxyporus sp. and 2
Chytridiomycetes, Chytriomyces hyalinus MP053 and Kappamyces sp. JEL356). Most of the fungi recovered in our study (24) were detected in the eutrophic LL, where fungi dominated the eukaryotic diversity for both seasons (Fig. 4). Although fungi represented only $6 \%$ of the small eukaryotic diver-

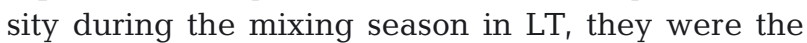
second most represented group after alveolates during the stratified season (Fig. 4). The environmental LTME6I sequence, which affiliated with the aquatic saprobe zoosporic fungus Coralloidiomyces digitatus (order Rhizophydiales) (Letcher et al. 2008c), was the only sequence detected during both mixing and stratified seasons. The majority of environmental fungal sequences (83\%) belonged to zoosporic fungi.

The phylogenetic placement of the 28S rDNA zoosporic fungal sequences is shown in Fig. 5. Maxi- 


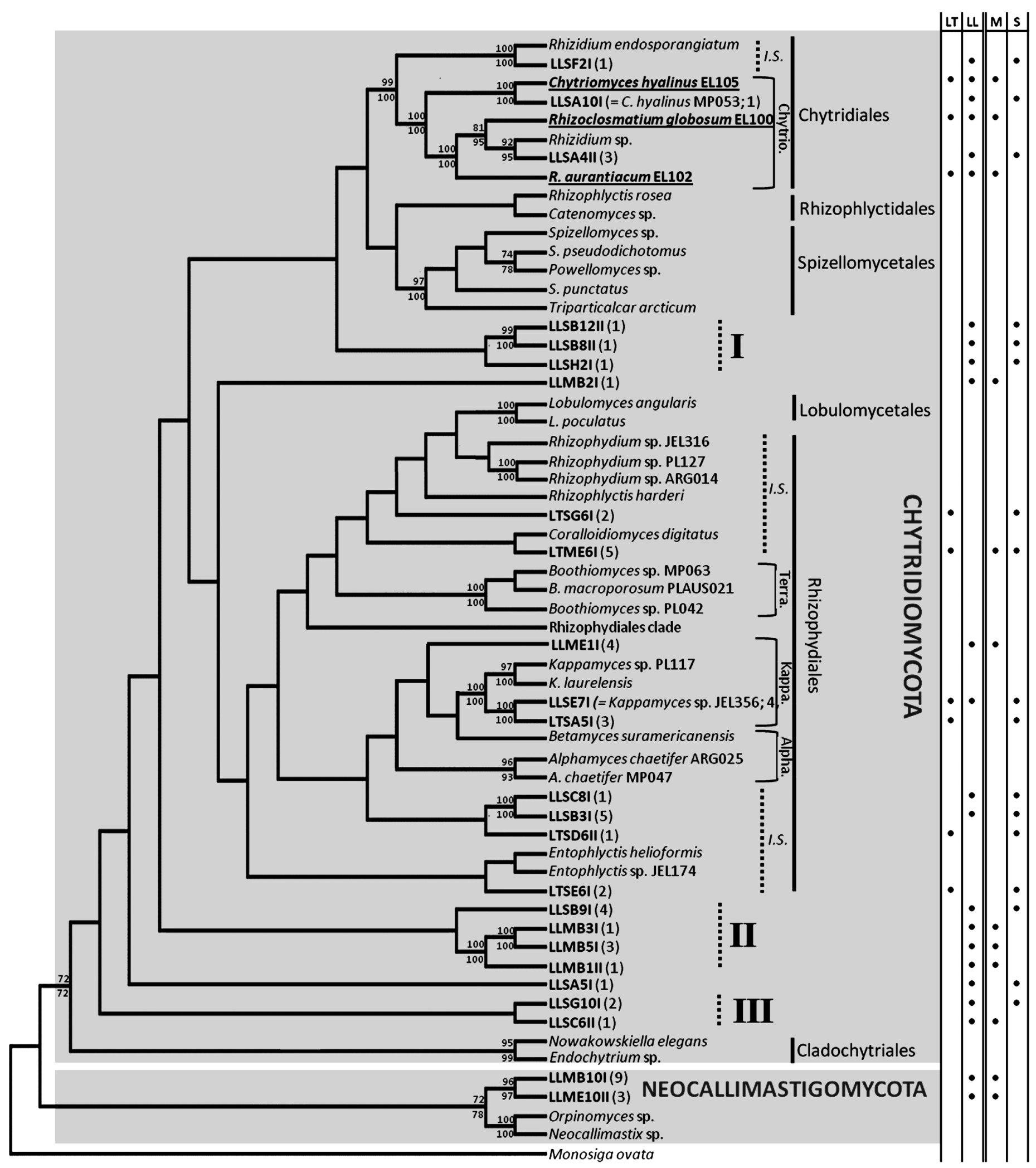

Fig. 5. Maximum likelihood phylogenetic tree of the basal fungi (i.e. zoosporic fungi) including a total of 60 partial $28 \mathrm{~S}$ rRNA sequences (28 recovered from the present study, in bold, and 32 obtained from GenBank, Table S1 in the supplement). Support values ( $\geq 70 \%)$ above and below the nodes are bootstrap values derived from maximum likelihood and maximum parsimony analyses, respectively. Taxa that were cultured are underlined. For each environmental sequence, the number of clones retrieved in our clone libraries is indicated in parentheses. Novel environmental clades are indicated by the Roman numerals I, II, and III. Hierarchical classification is given to the right of the tree. Occurrence of sequences in Lake Tuscaloosa (LT) and Lake Lurleen (LL), during the mixing (M) and the stratified (S) seasons are indicated (•) adjacent to the tree. Chytrio.: Chytriomycetaceae, Terra.: Terramycetaceae, Kappa.: Kappamycetaceae, Alpha.: Alphamycetaceae, I.S.: incertae sedis 
mum parsimony ( $\mathrm{L}=2478$ steps) and maximum likelihood $(-\ln L=15978.78$, using the GTR $+\mathrm{I}+\Gamma$ model of evolution) phylogenies were identical, with similar support values at major nodes; thus, only the ML tree is shown (Fig. 5). Within the phylogeny, strong support ( $>70 \%$ ) occurred primarily at terminal branches as well as at the divergence of Chytridiomycota from Neocallimastigomycota $(72 \%)$. The remainder of the backbone was not strongly supported. However, distinct and recognizable monophyletic groups in the inferred phylogeny are congruent with major clades in Chytridiomycota and Neocallimastigomycota (James et al. 2006a,b) that have been previously delineated, including Spizellomycetales (Barr 1980), Rhizophydiales (Letcher et al. 2006), Rhizophlyctidales (Letcher et al. 2008b), Cladochytriales (MozleyStandridge et al. 2009), Lobulomycetales (Simmons et al. 2009), and Chytridiales (Vélez et al. 2011). Half of the zoosporic fungal sequences obtained grouped within previously delineated orders of Chytridiomycota, (i.e. Chytridiales and Rhizophydiales). The other half formed clades that did not include any known or described zoosporic fungi. Three species of zoosporic fungi belonging to the order Chytridiales (Vélez et al. 2011) were isolated from both LT and LL (Fig. 6). Based on microscopic observation of the thallus (Fig. 6) and 28S rDNA partial sequences, 2 isolates were identified as Chytriomyces hyalinus (EL105) and Rhizoclosmatium globosum (EL100) (Fig. 6). The third isolate was identified as Rhizoclosmatium aurantiacum (EL102) according to the morphological characteristics of its thallus (Sparrow 1960) (Fig. 6). Only 5 of the 28 zoosporic fungi cultured (EL100, EL102, and EL105) or detected (LLSA10I = Chytriomyces hyalinus and LLSE7I = Kappamyces sp.) in our study had been previously
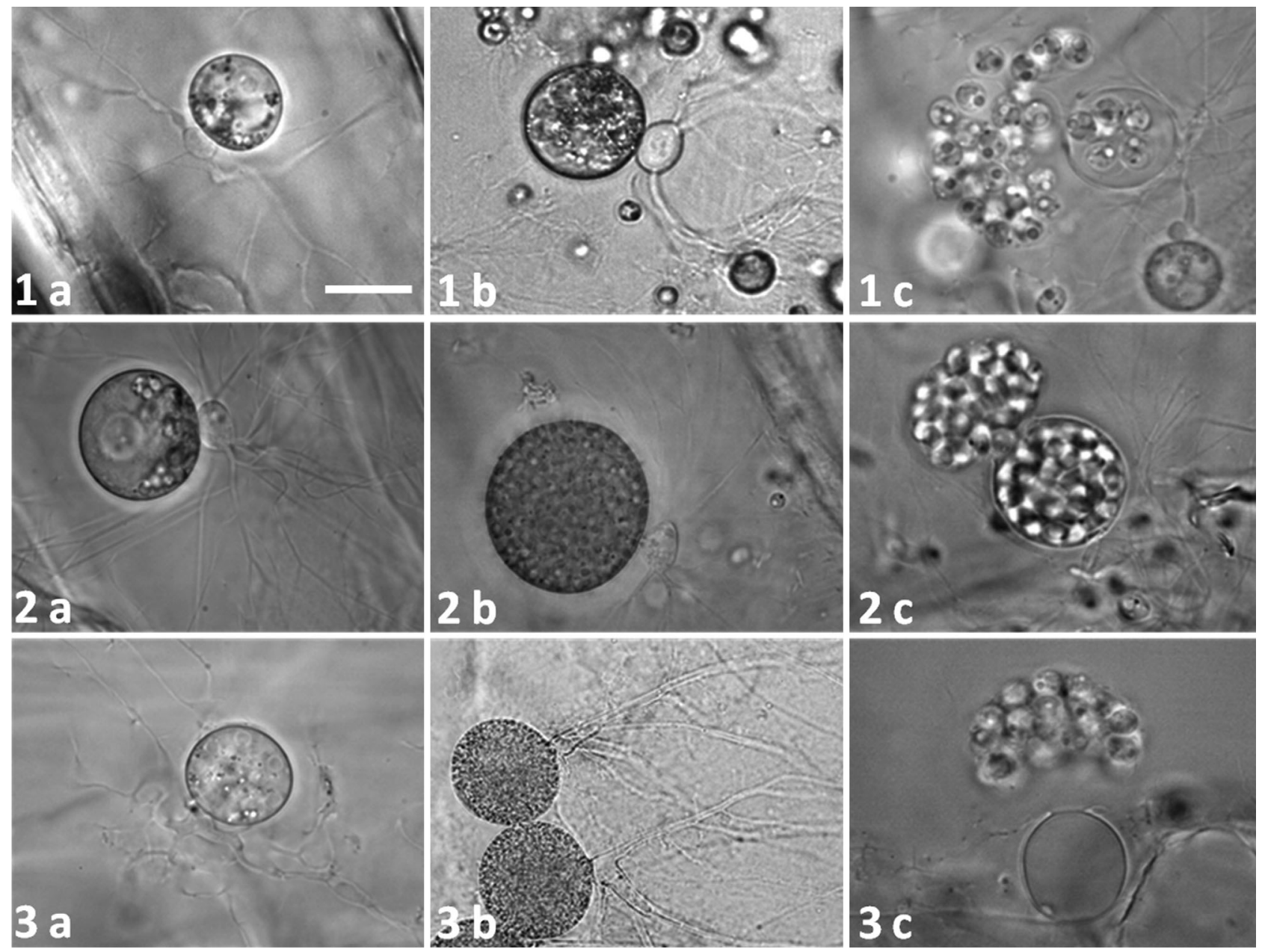

Fig. 6. Morphology of the 3 zoosporic fungi isolated from Lake Tuscaloosa and Lake Lurleen: (1) Rhizoclosmatium globosum EL100, (2) Rhizoclosmatium aurantiacum EL102, and (3) Chytriomyces hyalinus EL105 (a) germlings, (b) developing thalli, and (c) zoospore discharge. Scale bar in $1 \mathrm{a}=20 \mu \mathrm{m}$ for all micrographs 
isolated and described (Fig. 5). All of these except for LLSA10I were detected in both lakes.

The environmental clades I, II, and III as well as the lineages LLMB2I and LLSA5I were only found in LL. The remaining environmental sequences from LL grouped within Chytridiales, Rhizophydiales, and Neocallimastigomycota, whereas all environmental sequences from LT grouped within Rhizophydiales (Fig. 5). Within the Rhizophydiales, only 3 sequences (LLME1I, LTSA5I, and LLSE7I) fell into a known family, Kappamycetaceae (Letcher et al. 2008a). The other sequences grouped with phylogenetically unresolved taxa (incertae sedis). Within the order Chytridiales, however, all detected sequences except for LLSF2I (Fig 5) fell within the family Chytriomycetaceae (Vélez et al. 2011).

\section{DISCUSSION}

\section{Study sites}

LT and LL are located in the same geographic area and exhibited similar seasonal stratification regimes (Fig. 1). However, based on chlorophyll a concentration and Secchi depth measurements, LT and LL were characterized as oligotrophic and mesoeutrophic, respectively (Fig. S3 in the supplement at www.int-res.com/articles/suppl/a067p091_supp.pdf). The metalimnic oxygen minimum observed in LT, resulting from the activity of heterotrophic organisms, and maximum in LL (Fig. 1), resulting from autotrophic organisms, indicated that these 2 lake systems fundamentally differed in their functioning (Wetzel 2001). In addition, the dark color of LT water, a result of a high concentration of humic compounds in this lake (Wetzel 2001), likely prevents the production of a high algal biomass, supporting the development of heterotrophic microorganisms. These observations suggest that the 2 lakes differ in their carbon source and microbial food web structure and, thus, constituted ideal contrasting sites for comparing microbial communities.

\section{Overview of the small eukaryotic diversity}

Our study is the first to target the LSU gene in lakes. Previous similar studies used the SSU gene (Lefranc et al. 2005, Richards et al. 2005, Slapeta et al. 2005, Lefèvre et al. 2007, 2008, Chen et al. 2008, Lepère et al. 2008, Genitsaris et al. 2009, Luo et al. 2011, Monchy et al. 2011). Nevertheless, some of the general results obtained in our study are in accordance with the findings of previous studies: (1) the most represented taxa in our genetic libraries were fungi, alveolates, stramenopiles and cryptophytes, (2) heterotrophs were phylogenetically the most diverse among the small eukaryotic community, (3) Cryptophyta was the most diverse taxon among the small phototrophic eukaryotes, and (4) only few taxa were found in common in the 2 lakes studied. These results suggest that the overall structure of the small eukaryotic community is similar in a wide range of freshwater lakes. However, at a lower phylogenetic level, the structure of the eukaryotic community seems to be determined by the local characteristics of a lake.

A link between trophic level and the small eukaryotic community structure in lakes has been proposed (Lefranc et al. 2005, Chen et al. 2008, Lepère et al. 2008). Results from these studies suggested that the diversity of the small eukaryotic community tended to be lower in more productive waters. In the present study, the meso-eutrophic LL displayed a slightly higher diversity than the oligotrophic LT. However, this result might only reflect the fact that fewer clones were analyzed in LT libraries (211) compared to LL libraries (244). Therefore, the small eukaryotic community is possibly not more diversified in the meso-eutrophic LL compared to the oligotrophic LT.

Although our sampling effort was slightly lower during the stratification (i.e. 102 and 112 clones analyzed for LT and LL, respectively) than during the mixing season (i.e. 109 and 132 clones analyzed for LT and LL, respectively), the number of recovered OTUs was higher during the stratified season. However, more intensive sampling is necessary to establish a clear relationship between eukaryotic diversity and thermal stratification.

\section{Zoosporic fungal diversity and phylogeny}

With the exception of 1 study (Richards et al. 2005), zoosporic fungi have been systematically detected in lakes (Lefranc et al. 2005, Lefèvre et al. 2007, 2008, Lepère et al. 2008, Genitsaris et al. 2009, Luo et al. 2011, Monchy et al. 2011). Because some previous studies comparing aquatic systems differing in their trophic status found that zoosporic fungal diversity was higher in oligotrophic waters (Lefranc et al. 2005, Chen et al. 2008, Monchy et al. 2011), the oligotrophic LT was expected to harbor a higher zoosporic fungal diversity than the mesoeutrophic LL. However, the zoosporic fungal diver- 
sity was generally higher in the more eutrophic lake (Fig. 4). Table 2 summarizes environmental eukaryotic molecular surveys conducted in several lakes differing in trophic status and in which zoosporic fungal sequences were detected. Although comparison among these studies is difficult because experimental designs (season, depth, and size fraction sampled), methodologies, and data analyses (sampling effort, PCR primers, and sequence percentage similarity cut-offs) differed (Table 2), no obvious relationship between zoosporic fungal diversity and trophic status could be suggested. In contrast to the present study, which used integrated samples (i.e. several sampling points in time were pooled), previous environmental molecular surveys (Table 2) only analyzed 1 or 2 samples isolated in time collected during various seasons of the year. Thus, although data from numerous studies are available (Table 2), it might be too early to establish a clear relationship between trophic status and zoosporic fungal community structure.

Previous studies have found that the zoosporic fungal community in lakes was either affiliated with members of the Rhizophydiales and Chytridiales or formed environmental clades (i.e. with no cultured or described species) (Lefèvre et al. 2007, 2008, Lepère et al. 2008, Monchy et al. 2011). In the design of the present study, we hypothesized that the systematic recovery of environmental clades of zoosporic fungi in previous surveys might have been related to the lack of representative fungal sequences in the constructed phylogeny. The LSU gene has been widely used in the taxonomy of lower fungi (i.e. zoosporic fungi) (Tanabe et al. 2005, Letcher et al. 2005, 2006, 2008a,b,c, James et al. 2006a,b, Hibbett et al. 2007, Mozley-Standridge et al. 2009, Simmons et al. 2009, Wakefield et al. 2010). Thus, because of the greater availability of LSU sequences, we expected our retrieved sequences to primarily fall into described taxa of zoosporic fungi. Surprisingly, our results were similar to what was obtained in previous studies, with half of our sequences affiliated with described zoosporic fungal taxa and the other half forming environmental clades. This suggests that the environmental clades detected in previous studies were not an artifact due to the lack of fungal sequences used as references in the phylogeny but actual environmental clades for which zoosporic fungi have not yet been described. Thus, our study confirms that lakes are undersampled for zoosporic fungal diversity and that these ecosystems harbor a highly unexplored zoosporic fungal diversity mainly within the order Chytridiales and Rhizo- phydiales, known to contain both saprobes and algal parasites (Letcher et al. 2008a, Vélez et al. 2011). Interestingly, 2 environmental sequences (LLMB10I and LLMBE10II) affiliated to Neocallimastigomycota, which are known to be essentially anaerobic (Liggenstoffer et al. 2010), were detected. Only 1 previous similar study conducted by Slapeta et al. (2005) in a shallow freshwater pond also detected 1 environmental sequence related to this phylum. Although these sequences were detected in the plankton, they could actually originate from anaerobic sediments.

A majority of the zoosporic fungi detected in our molecular survey were only found in 1 lake and were only represented by few clones in our libraries (Fig. 5). This suggests that the zoosporic fungi detected by the molecular survey are probably part of the 'rare biosphere' (Sogin et al. 2006), supporting the idea that molecular surveys tend to detect less abundant ('rare') species, while culture methods are selective for more common species. The isolation of only 3 zoosporic fungi with selective baiting techniques in the present study highlights the difficulty of adequately culturing zoosporic fungi from aquatic systems. Although zoosporic fungal isolation from the small planktonic fraction (0.6 to $8 \mu \mathrm{m})$ was attempted in the present study, only isolates from the fraction collected using the plankton tow $(>60 \mu \mathrm{m})$ were obtained. Thus, since our sampling strategy differed between culturing and molecular approaches, comparison of the diversity obtained between the 2 methods cannot be made. In addition, as the baiting technique only selects for saprobes and facultative algal parasites (Letcher \& Powell 2001, 2002, Letcher et al. 2004b, 2008a,b, Wakefield et al. 2010), zoosporic fungi that are obligate parasites on phytoplankton and known to be diverse and recurrent in lake ecosystems (Gromov et al. 1999, Ibelings et al. 2004, Kagami et al. 2007b, Rasconi et al. 2009, 2012, Sønstebø \& Rohrlack 2011) remain undetected using culturing methods.

Previous studies have shown that fungal sporangia are commonly observed attached to planktonic algae (Kagami et al. 2007b, Rasconi et al. 2009, 2012). Although fungal epidemics of phytoplanktonic populations are a recurrent phenomenon in lakes (Canter \& Lund 1951, van Donk \& Ringelberg 1983, Kagami \& Urabe 2002, Miki et al. 2011), the mechanisms underlying the dynamics of parasitic fungi on phytoplankton are not well understood. Rasconi et al. $(2009,2012)$ suggested that the community of algal parasitic fungi might be more related to the community composition of their host 


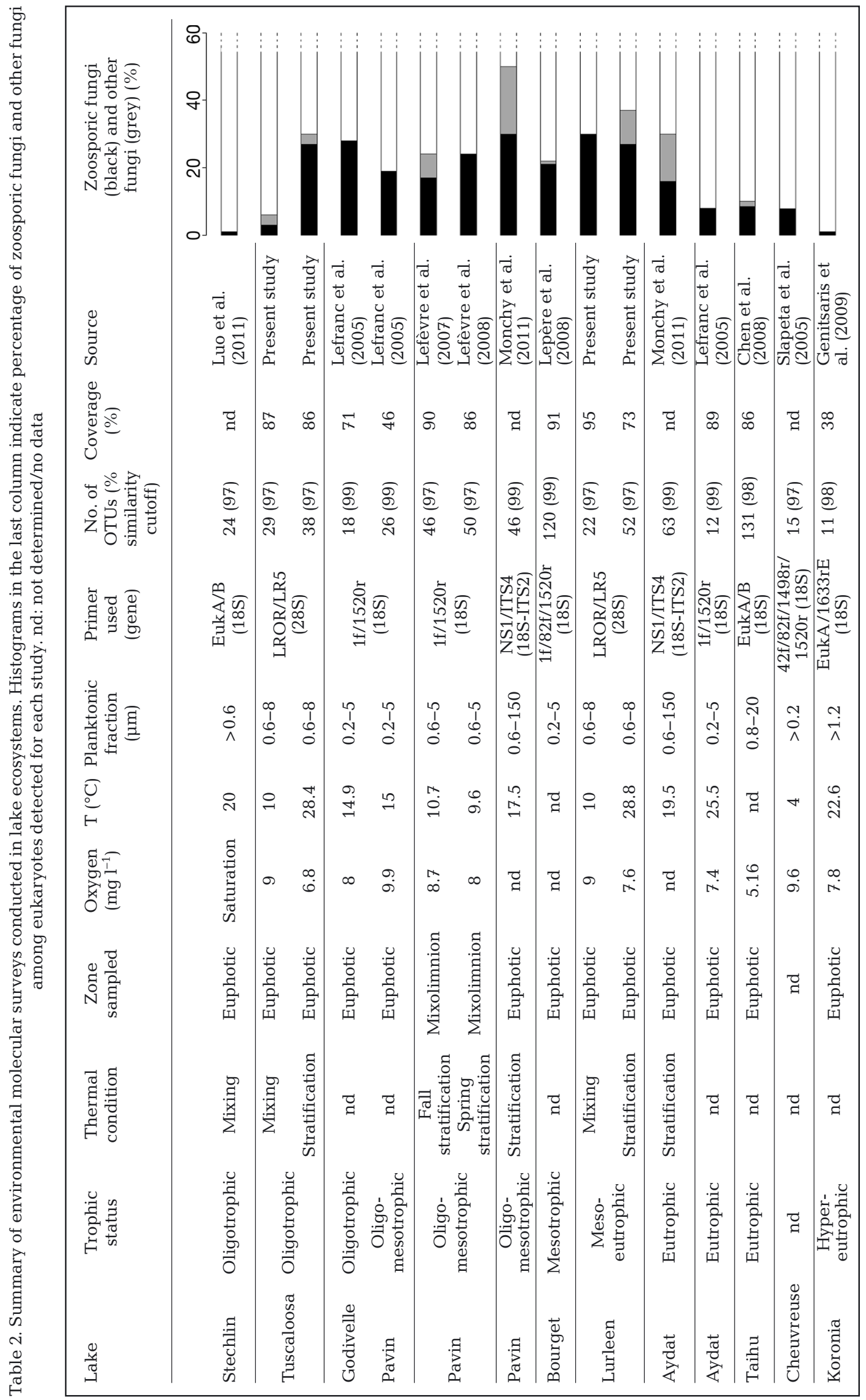


than the trophic status of the lake. Indeed, the higher algal biomass in LL, which represents a higher abundance of potential hosts for parasitic zoosporic fungi, could explain the higher diversity detected in LL. Similarly in LT, the more diverse algal community during the stratified season could also potentially explain the higher diversity of zoosporic fungal community during this season. However, although fungal sporangia were observed on several algal species in both lakes (Fig. 3), their occurrence was very low, suggesting that most of the zoosporic fungi detected in our clone libraries were saprobes. Therefore, it seems unlikely that the composition and dynamics of the phytoplanktonic community explains the temporal variation of the zoosporic fungal community in LT and LL. Quantitative methods have recently been developed to detect zoosporic fungi in aquatic ecosystems (Rasconi et al. 2009, Jobard et al. 2010, Lefèvre et al. 2010). However, more adapted and specific methods are needed for the study of the zoosporic fungal community. In the present study, LROR and LR5 primers, although widely used for zoosporic fungal taxonomy (James et al. 2006a,b, Letcher et al. 2008a,c, Mozley-Standridge et al. 2009, Wakefield et al. 2010), amplified various other eukaryotes. The availability of specific fungal primers represents a major limitation for the molecular detection of fungi in natural environments. Primers initially designed to target fungi, nu-SSU-0817-5'/nu-SSU-1196-3' (Borneman \& Hartin 2000) and FF390/FR1 (Vainio \& Hantula 2000), once used in molecular environmental surveys in lake ecosystems (Monchy et al. 2011 [nu-SSU-0817-5'/nu-SSU-1196-3'], Kagami et al. 2012 [FF390/FR1]), also target an important proportion of eukaryotes (81 to $91 \%$ of sequences detected using nu-SSU-0817-5' and nu-SSU-1196-3' fungal primers were not fungal sequences) (Monchy et al. 2011). These methodological limitations stress the importance of developing new techniques adapted to the isolation and detection of zoosporic fungi from truly aquatic habitats. In addition, direct observation and identification of zoosporic fungi in natural samples is a very difficult task due to their small size and lack of distinctive morphological characteristics (Powell 1993, Lefèvre et al. 2007, 2008, Kagami et al. 2012). The molecular data generated from lake surveys will provide greater possibilities for the design of specific primers and the development of molecular techniques allowing quantification of zoosporic fungi in lakes, thus improving our understanding of their fundamental importance in pelagic microbial food webs.
Acknowledgements. The present study was supported in part by National Science Foundation grants DEB-0516173 and DEB-0949305 and the Ecology and Systematics Biology Enhancement Award from The University of Alabama. We express our appreciation to M. Dedmon for his assistance with sampling.

\section{LITERATURE CITED}

Barr DJS (1980) An outline for the reclassification of the Chytridiales, and for a new order, the Spizellomycetales. Can J Bot 58:2380-2394

Borneman J, Hartin RJ (2000) PCR primers that amplify fungal rRNA genes from environmental samples. Appl Environ Microbiol 66:4356-4360

Canter HM, Lund JWG (1951) Studies on plankton parasites. III. Examples of the interaction between parasitism and other factors determining the growth of diatoms. Ann Bot (Lond) 15:359-371

Carlson RE (1977) A trophic state index for lakes. Limnol Oceanogr 22:361-369

Chen M, Chen F, Yu Y, Ji J, Kong F (2008) Genetic diversity of eukaryotic microorganisms in Lake Taihu, a large shallow subtropical lake in China. Microb Ecol 56:572-583

Freeman KR, Martin AP, Karli D, Lynch RC and others (2009) Evidence that chytrids dominate fungal communities in high-elevation soils. Proc Natl Acad Sci USA 106: 18315-18320

Fuller MS, Jaworski A (1987) Zoosporic fungi in teaching and research. Southeastern Publishing, Athens, GA

Genitsaris S, Kormas KA, Moustaka-Gouni M (2009) Microscopic eukaryotes living in a dying lake (Lake Koronia, Greece). FEMS Microbiol Ecol 69:75-83

Gleason FH, Kagami M, Lefèvre E, Sime-Ngando T (2008) The ecology of chytrids in aquatic ecosystems: roles in food web dynamics. Fungal Biol Rev 22:17-25

Gromov BV, Pljusch AV, Mamkaeva KA (1999) Morphology and possible host range of Rhizophydium algavorum sp. nov (Chytridiales) and obligate parasite of algae. Protistology 1:62-65

Hall TA (1998) BioEdit: a user-friendly biological sequence alignment editor and analysis program for Windows 95/98/NT. Nucleic Acids Symp Ser 41:95-98

Hibbett DS, Binder M, Bischoff JF, Blackwell M and others (2007) A higher-level phylogenetic classification of the Fungi. Mycol Res 111:509-547

- Hillebrand H, Durselen CD, Kirshtel D, Pollingher U, Zohari $\mathrm{T}$ (1999) Biovolume calculation for pelagic and benthic microalgae. J Phycol 35:403-424

> Ibelings BW, de Bruin A, Kagami M, Rijkeboer M, Brehm M, Van Donk E (2004) Host parasite interactions between freshwater phytoplankton and chytrid fungi (Chytridiomycota). J Phycol 40:437-453

> James TY, Letcher PM, Longcore JE, Mozley-Standridge SE and others (2006a) A molecular phylogeny of the flagellated fungi (Chytridiomycota) and description of a new phylum (Blastocladiomycota). Mycologia 98:860-871

James TY, Kauff F, Schoch CL, Matheny PB and others (2006b) Reconstructing the early evolution of the fungi using a six gene phylogeny. Nature 443:818-822

Jobard M, Rasconi S, Sime-Ngando T (2010) Fluorescence in situ hybridization of uncultured zoosporic fungi: testing with clone-FISH and application to freshwater samples using CARD-FISH. J Microbiol Methods 83:236-243 
Kagami M, Urabe J (2002) Mortality of the planktonic desmid, Staurastrum dorsidentiferum, due to interplay of fungal parasitism and low light conditions. Verh Internat Verein Limnol 28:1001-1005

- Kagami M, van Donk E, de Buin A, Rijkeboer M, Ibelings BW (2004) Daphnia can protect diatoms from fungal parasitism. Limnol Oceanogr 49:680-685

- Kagami M, von Elert E, Ibelings BW, de Bruin A, van Donk E (2007a) The parasitic chytrid, Zygorhizidium, facilitates the growth of the cladoceran zooplankter, Daphnia, in cultures of the inedible alga, Asterionella. Proc Biol Sci 274:1561-1566

> Kagami M, de Bruin A, Ibelings BW, van Donk E (2007b) Parasitic chytrids: their effects on phytoplankton communities and food-web dynamics. Hydrobiologia 578: 113-129

Kagami M, Yosuke A, Nobuyoshi I (2012) Community structure of planktonic fungi and the impact of parasitic chytrids on phytoplankton in Lake Inba, Japan. Microb Ecol 63:358-368

Le Calvez T, Burgaud G, Mahé S, Barbier G, Vandenkoornhuyse P (2009) Fungal diversity in deep-sea hydrothermal ecosystems. Appl Environ Microbiol 75:6415-6421

- Lee SM, Chao A (1994) Estimating population size via sample coverage for closed capture-recapture models. Biometrics 50:88-97

> Lefèvre E, Bardot C, Noël C, Carrias JF, Viscogliosi E, Amblard C, Sime-Ngando T (2007) Unveiling fungal zooflagellates as members of freshwater picoeukaryotes: evidence from a molecular diversity study in a deep meromictic lake. Environ Microbiol 9:61-71

Lefèvre E, Roussel B, Amblard C, Sime-Ngando T (2008) The molecular diversity of freshwater picoeukaryotes reveals high occurrence of putative parasitoids in the plankton. PLoS ONE 3:e2324

> Lefèvre E, Jobard M, Venisse JS, Bec A, Kagami M, Amblard C, Sime-Ngando T (2010) Development of a Real-Time PCR assay for quantitative assessment of uncultured freshwater zoosporic fungi. J Microbiol Methods 81:69-76

> Lefranc M, Thénot A, Lepère C, Debroas D (2005) Genetic diversity of small eukaryotes in lakes differing by their trophic status. Appl Environ Microbiol 71: 5935-5942

> Lepère C, Domaizon I, Debroas D (2008) Unexpected importance of potential parasites in the composition of the freshwater small-eukaryote community. Appl Environ Microbiol 74:2940-2949

Letcher PM, Powell MJ (2001) Distribution of zoosporic fungi in forest soils of the Blue Ridge and Appalachian Mountains of Virginia. Mycologia 93:1029-1041

Letcher PM, Powell MJ (2002) Frequency and distribution patterns of zoosporic fungi from moss-covered and exposed soils. Mycologia 94:761-771

> Letcher PM, Powell MJ (2005a) Kappamyces, a new genus in the Chytridiales (Chytridiomycota). Nova Hedwigia 80:115-133

> Letcher PM, Powell MJ (2005b) Phylogenetic position of Phlyctochytrium planicorne (Chytridiales, Chytridiomycota) based on zoospore ultrastructure and partial nuclear LSU rRNA gene sequence analysis. Nova Hedwigia 80:135-146

Letcher PM, Powell MJ, Chambers JG, Holznagel WE (2004a) Phylogenetic relationships among Rhizophydium isolates from North America and Australia.
Mycologia 96:1339-1351

Letcher PM, McGee PA, Powell MJ (2004b) Diversity of chytrids from soils of four vegetation types in New South Wales Australia. Can J Bot 82:1490-1500

$>$ Letcher PM, Powell MJ, Chambers JG, Longcore JE, Churchill PF, Harris PM (2005) Ultrastructural and molecular delineation of the Chytridiaceae (Chytridiales). Can J Bot 83:1561-1573

Letcher PM, Powell MJ, Churchill PF, Chambers JG (2006) Ultrastructural and molecular phylogenetic delineation of a new order, the Rhizophydiales. Mycol Res 110: 898-915

Letcher PM, Vélez CG, Barrantes ME, Powell MJ, Churchill PF, Wakefield WS (2008a) Ultrastructural and molecular analyses of Rhizophydiales (Chytridiomycota) isolates from North America and Argentina. Mycol Res 112: 759-782

> Letcher PM, Powell MJ, Barr DJS, Churchill PF, Wakefield WS, Picard KT (2008b) Rhizophlyctidales-a new order in Chytridiomycota. Mycol Res 112:1031-1048

Letcher PM, Powell MJ, Viusent MC (2008c) Rediscovery of an unusual chytridiaceous fungus new to the order Rhizophydiales. Mycologia 100:325-334

Liggenstoffer AS, Youssef NH, Couger MB, Elshahed MS (2010) Phylogenetic diversity and community structure of anaerobic gut fungi (phylum Neocallimastigomycota) in ruminant and non-ruminant herbivores. ISME $\mathrm{J} 4$ : 1225-1235

Luo W, Bock C, Li HR, Padisak J, Krienitz L (2011) Molecular and microscopic diversity of planktonic eukaryotes in the oligotrophic Lake Stechlin (Germany). Hydrobiologia 661:133-143

Miki T, Takimoto G, Kagami M (2011) Roles of parasitic fungi in aquatic food webs: a theoretical approach. Freshw Biol 56:1173-1183

Monchy S, Sanciu G, Jobard M, Rasconi S and others (2011) Exploring and quantifying fungal diversity in freshwater lake ecosystems using rDNA cloning/sequencing and SSU tag pyrosequencing. Environ Microbiol 13: 1433-1453

Mozley-Standridge SE, Letcher PM, Longcore JE, Porter D, Simmons DR (2009) Cladochytriales - a new order in Chytridiomycota. Mycol Res 113:498-507

- Nagahama T, Takahashi E, Nagano Y, Abdel-Wahab MA, Masayuki M (2011) Molecular evidence that deepbranching fungi are major components in deep-sea methane cold-seep sediments. Environ Microbiol 13: 2359-2370

Nikolcheva LG, Bärlocher F (2004) Taxon-specific fungal primers reveal unexpected high diversity during leaf decomposition in a stream. Mycol Prog 3:41-49

Posada D, Crandall KA (1998) Modeltest: testing the model of DNA substitution. Bioinformatics 14:817-818

Powell MJ (1993) Looking at mycology with a Janus face: a glimpse at Chytridiomycetes active in the environment. Mycologia 85:1-20

Rasconi S, Jobard M, Jouve L, Sime-Ngando T (2009) Use of calcofluor white for detection, identification, and quantification of phytoplanktonic fungal parasites. Appl Environ Microbiol 75:2545-2553

> Rasconi S, Niquil N, Sime-Ngando T (2012) Phytoplankton chytridiomycosis: community structure and infectivity of fungal parasites in aquatic ecosystems. Environ Microbiol 14:2151-2170

Richards TA, Vepritskiy AA, Gouliamova DE, Nierzwicki- 
Bauer SA (2005) The molecular diversity of freshwater picoeukaryotes from an oligotrophic lake reveals diverse, distinctive and globally dispersed lineages. Environ Microbiol 7:1413-1425

Seena S, Wynberg N, Bärlocher F (2008) Fungal diversity during leaf decomposition in a stream assessed through clone libraries. Fungal Divers 30:1-14

Sigee DC (2005) Freshwater microbiology: biodiversity and dynamic interactions of microorganisms in the freshwater environment. John Wiley and Sons, Chichester

Sikes DS, Lewis PO (2001) Beta software, version 1. PAUPRat: PAUP* implementation of the parsimony ratchet. Distributed by the authors. Department of Ecology and Evolutionary Biology, University of Connecticut, Storrs, CT

Simmons DR, James TY, Meyer AF, Longcore JE (2009) Lobulomycetales, a new order in the Chytridiomycota. Mycol Res 113:450-460

Slapeta J, Moreira D, Lopez-Garcia P (2005) The extent of protist diversity: insights from molecular ecology of freshwater eukaryotes. Proc Biol Sci 272:2073-2081

Smith G (1950) The freshwater algae of the United States, 2nd edn. McGraw-Hill Book Company, Stanford, CA

Sogin ML, Morrison HG, Huber JA, Welch DM and others (2006) Microbial diversity in the deep sea and the unexplored 'rare biosphere'. Proc Natl Acad Sci USA 103: 12115-12120

Sønstebø JH, Rohrlack T (2011) Possible implications of chytrid parasitism for population subdivision in freshwater cyanobacteria of the genus Planktothrix. Appl Environ Microbiol 77:1344-1351

Sparrow FK (1960) Aquatic phycomycetes, 2nd edn. The University of Michigan Press, Ann Arbor, MI

Swofford DL (2002) PAUP*: phylogenetic analysis using parsimony ( ${ }^{*}$ and other methods), Version 4.0b10. Sinauer Associates, Sunderland, MA

Tanabe Y, Watanabe MM, Sugiyama J (2005) Evolutionary relationship among basal fungi (Chytridiomycota and Zygomycota): insights from molecular phylogenetics. J Gen Appl Microbiol 51:267-276

Thompson JD, Gibson TJ, Plewniak F, Jeanmougin F, Hig-

Editorial responsibility: Daniel Vaulot,

Roscoff, France gins DG (1997) The ClustalX windows interface: flexible strategies for multiple sequence alignment aided by quality analysis tools. Nucleic Acids Res 25:4876-4882

> Vainio EJ, Hantula J (2000) Direct analysis of wood-inhabiting fungi using denaturing gradient electrophoresis of amplified ribosomal DNA. Mycol Res 104:927-936

> van Donk H, Ringelberg J (1983) The effect of fungal parasitism on the succession of diatoms in Lake Maarsseveen I (The Netherlands). Freshw Biol 13:241-251

> Vélez CG, Letcher PM, Schultz S, Powell MJ (2011) Molecular phylogenetic and zoospore ultrastructural analyses of Chytridium olla establish the limits of a monophyletic Chytridiales. Mycologia 103:118-130

Vilgalys R, Hester M (1990) Rapid genetic identification and mapping of enzymatically amplified ribosomal DNA from several Cryptococcus species. J Bacteriol 172: 4238-4246

- Wakefield WS, Powell MJ, Letcher PM, Barr DJF, Churchill PF, Longcore JE, Chen SF (2010) A molecular phylogenetic evaluation of the Spizellomycetales. Mycologia 102:596-604

Ward GM, Harris PM, Ward AK (2005) Gulf Coast rivers of the southeastern United States. In: Benke AC, Cushing CE (eds) Rivers of North America. Elsevier Academic Press, Oxford, p 56-77

Wehr JD, Sheath RG (2003) Freshwater algae of North America: ecology and classification. Academic Press, San Diego, CA

Wetzel RG (2001) Limnology: lake and river ecosystems, 3rd edn. Academic Press, San Diego, CA

Wetzel RG, Likens GE (1990) Limnological analyses, 3rd edn. Springer, New York, NY

White TJ, Bruns TD, Lee SB, Taylor JW (1990) Amplification and direct sequencing of fungal ribosomal RNA genes for phylogenetics. In: Innis MA, Gelfand DH, Sninsky JJ, White TJ (eds) PCR protocols: a guide to methods and applications. Academic Press, London, p 315-322

Zwickl DJ (2006) Genetic algorithm approaches for the phylogenetic analysis of large biological sequence datasets under the maximum likelihood criterion. PhD dissertation, University of Texas, Austin, TX

Submitted: April 30, 2012; Accepted: August 5, 2012

Proofs received from author(s): September 24, 2012 